\title{
Relação gestos/sinais em Libras: uma análise baseada no contínuo de Cornelia Müller
}

\author{
Marcelo PORTO (1) \\ Universidade Federal do Paraná (UFPR)
}

อ

\section{OPEN ACCESS}

EDITADO POR

- Raquel Freitag (UFS)

AVALIADO POR

- André Xavier (UFPR)

- Angélica Rodrigues (UNESP)

DATAS

- Recebido: 02/08/2021

- Aceito: 12/09/2021

- Publicado: 22/09/2021

COMO CITAR

Porto, M. (2021). Relação gestos/sinais em Libras: uma análise baseada no contínuo de Cornelia Müller. Revista da Abralin, v. 20, n. 2, p. 1-25, 2021.

\section{RESUMO}

No início dos estudos das línguas de sinais, os pesquisadores limitaram-se a argumentar sobre a dimensão sistêmica dessas línguas, sem considerar a questão da gestualidade. Atualmente, entretanto, o estatuto da gestualidade nos estudos das línguas de sinais tem se tornado objeto de reflexão com a ascensão de diferentes perspectivas teóricas. Este trabalho situa-se nesse contexto e visa a refletir criticamente sobre a proposta teórica de Müller (2019) acerca da relação de gestos/sinais tanto no âmbito dos estudos de línguas orais quanto no das de sinais, explorando sua teoria empiricamente na Língua Brasileira de Sinais (Libras). Müller (2019) propõe um contínuo gestual composto por gestos singulares, gestos recorrentes, emblemas e sinais, e tal proposta é discutida por meio de uma metodologia descritiva e interpretativa baseada em dados em Libras da "história da pera" criada pelo linguista Wallace Chafe (1980) em Libras. Os resultados indicam a possibilidade de a maioria das ações manuais na narrativa atenderem aos critérios de convencionalidade, composicionalidade e relação forma-significado definidos pela autora, mas também levantam questões no que diz respeito às realizações de boias e de sinais em contextos de ação construída em Libras. Como conclusão, apontamos para a insuficiência de uma abordagem gestual de cunho "lexicalista" para explicação dos fenômenos gestuais que ocorrem no campo discursivo das línguas de sinais e da Libras, na qual esta análise se baseia.

\section{ABSTRACT}

In the early days of studies with sign languages, researchers limited 


\section{REVISTA DA ABRALIN}

themselves to arguing about their structure, without considering the issue of gestures. However, currently gestures have gained strength in the studies of sign languages, through different theoretical perspectives. This study is part of that context and aims to critically reflect on Müller's (2019) theoretical proposal on the relationship between gestures and signs in the context of sign language studies, both from a theoretical and an empirical point of view in the Brazilian Sign Language (Libras). Müller (2019) proposes a continuum composed of singular gestures, recurrent gestures, emblems and signs, and this proposal will be discussed through descriptive and interpretive analysis based on Libras data related to "the pear story", created by Wallace Chafe (1980). The results point to the possibility of classifying manual actions that meet the criteria of conventionality, compositionality and form-meaning correspondence defined by the author, but also demonstrate the theoretical non-adherence to the realization of buoys and incorporation in Libras. Conclusively, we highlight the insufficiency of a lexicalist approach to explain linguistic phenomena that occur in the discursive field of sign languages and Libras, which this analysis is based on.

PALAVRAS-CHAVE

Gesto. Contínuo gestual. Sinais. Língua de sinais. Libras.

\section{KEYWORDS}

Gesture. Continuum. Signs. Brazilian sign language. Libras.

\section{Introdução}

Por muito tempo, as línguas de sinais foram consideradas uma representação da língua oral e sem uma gramática própria (GESSER, 2009). A partir dos estudos linguísticos, iniciados em 1960, esse quadro se reverteu de modo que a Linguística das Línguas de Sinais construiu aportes significativos que demarcaram seu status linguístico e demonstraram suas propriedades como língua natural. Nesses estudos, não havia qualquer menção aos elementos gestuais presentes na sinalização face a face, de modo a evitar o retorno aos mitos que outrora permearam as línguas de sinais, de que tais línguas seriam um mero agregado de gestos e pantomimas sem estruturação convencional e sistêmica.

Atualmente, entretanto, as discussões sobre as línguas de sinais têm acolhido os estudos dos gestos e articulado importantes constructos teóricos. A aproximação dessas duas áreas (linguística das línguas de sinais e estudo dos gestos), segundo Müller (2019), tem gerado grandes contribuições 


\section{REVISTA DA ABRALIN}

para ambas as áreas, entre as quais a nova percepção sobre a multimodalidade e a diversidade semiótica que envolvem as línguas humanas.

Nessa perspectiva atualizada dos estudos com a linguagem, em 2019 as pesquisadoras Wendy Sandler, Marianne Gullberg e Carol Padden publicaram, pelo periódico Frontiers in Psychology, um volume intitulado Visual Language, que reúne 19 artigos que abordam 4 principais tópicos: a natureza multimodal da linguagem, a representação multimodal do significado, a prosódia multimodal e multicanal e a aquisição e o desenvolvimento da linguagem visual em crianças e adultos.

A proposição desse volume parte da premissa de que língua e gestos exploram naturalmente a expressão visual e, portanto, precisam ser igualmente considerados em relação à linguagem humana. A principal contribuição da obra é o fato de levar o leitor a perceber que os pesquisadores das línguas de sinais não precisam mais excluir os gestos do estudo das línguas de sinais. Nesse sentido, consideramos que a leitura da coleção é imprescindível aos pesquisadores da linguística das línguas de sinais, haja vista que reúne textos inéditos que abordam os elementos visuais da linguagem.

No bojo do e-book Visual Language, encontra-se o trabalho de Müller (2019), cuja proposta teórica será objeto de análise neste artigo. A autora procurou fazer uma síntese histórica de como o "gesto" figurou no campo de pesquisa sobre as línguas de sinais; em seguida, a partir desse panorama histórico, introduziu a sua própria perspectiva teórica a respeito do tema. Na primeira parte do artigo, em que apresenta uma reconstrução da história da discussão acadêmica sobre a relação entre gestos e sinais, a autora interpreta os argumentos de Kendon (2014), por um lado, e de Goldin-Meadow (2015) e Goldin-Meadow e Brentari (2017) por outro - que, por sua vez, apoiam-se na teoria dos gestos advinda de McNeill (2000). Segundo a interpretação de Müller (2019), os trabalhos apresentam perspectivas distintas sobre a relação entre "língua" e "gesto", haja vista que Goldin-Meadow (2015) e Goldin-Meadow e Brentari (2017) oferecem uma visão de "ruptura cataclísmica" entre gestos e sinais, enquanto Kendon (2014) defende a ideia de que as relações entre essas dimensões são gradientes e dinâmicas. Alinhando-se à visão de Kendon (2014) e contrariando a de Goldin-Meadow (2015) e Goldin-Meadow e Brentari (2017), na segunda parte do artigo Müller (2019) lança mão de sua proposta teórica, que se fundamenta na mudança histórica de gesto para sinal (que inclui processos de lexicalização) e na comparação sincrônica entre línguas orais e de sinais. Seus argumentos, em geral, baseiam-se nos pressupostos de Kendon (2014).

O objetivo deste artigo é refletir criticamente sobre a proposta teórica que Müller (2019) delineia no seu texto, tanto do ponto de vista teórico quanto do empírico, por meio da análise de dados da Libras. Esses dados se baseiam em uma narrativa contada em Libras a partir do filme mudo conhecido como "história da pera" (CHAFE, 1980), que tem sido utilizado em investigações sobre diferentes línguas orais e de sinais. Os dados foram coletados do Corpus de Libras da Universidade Federal de Santa Catarina (UFSC, 2014) e, depois, analisados com base na proposta do contínuo definida por Müller (2019).

Na próxima seção, as concepções teóricas elaboradas na segunda parte do artigo Gesture and sign: cataclysmic break or dynamic relations? de Müller (2019) serão introduzidas com maiores detalhes. Em seguida, explicaremos a metodologia por meio da qual buscamos testar empiricamente a 


\section{REVISTA DA ABRALIN}

proposta teórica de Müller (2019), de modo a verificar de que maneira ela dialoga com os dados em Libras. Depois disso, apresentaremos a análise dos dados demonstrando os resultados que se alinham e os que desafiam a classificação do contínuo. Para essa discussão, optamos por usar a expressão "ação manual" ao nos referirmos à produção em Libras, de modo a não nos comprometermos aprioristicamente com uma ruptura entre esses elementos visuais da linguagem. As considerações finais serão apresentadas na última seção.

\section{A proposta teórica de Müller (2019)}

Müller (2019) afirma que seu conceito de "linguagem" pressupõe que as línguas humanas são multimodais e compostas de enunciados como instanciações da multimodalidade. Quanto ao conceito de "enunciado", a autora recorre a Janzen (2017), que se baseia em Enfield (2009) e diz tratar-se de "uma unidade completa de ação social que sempre tem múltiplos componentes, que está sempre inserida em um contexto sequencial" (JANZEN, 2017, p. 518 apud MÜLLER, 2019, p. 43).

A esse respeito, Müller (2019) exemplifica que uma manifestação típica de multimodalidade são os usos de gestos em coocorrência com a "fala" nas produções em língua oral, trazendo como exemplo a possibilidade de um falante narrar o tamanho de uma caixa mostrando, gestualmente, a sua forma enquanto emite a expressão vocal "da caixa". A autora afirma que essa é uma típica produção de enunciado multimodal, já que o significado total do que o falante está dizendo é um produto de uma interação entre os significados de sua fala vocal ("a caixa") e as representações visuais realizadas manualmente (o gesto que representa a sua forma e o seu tamanho).

Assim, apesar de Müller (2019) não desenvolver o conceito de "multimodalidade" em maiores detalhes, ela o adota como pano de fundo para a sua proposta teórica. De acordo com Capistrano Júnior, Lins e Casotti (2017, p. 288), a multimodalidade é concebida "como coocorrência de vários modos de representação/construção da linguagem (semioses), que se integram na construção de significados em interações sociais". Nesse sentido, entendemos que toda a produção em Libras é, igualmente, uma realização multimodal, pois utiliza vários modos semióticos para gerar sentido em diferentes contextos, cujos modos são "socialmente modelados ao longo do tempo e estão alicerçados em um senso cultural compartilhado em uma comunidade" (CAPISTRANO JÚNIOR; LINS; CASOTTI, 2017, p. 288).

A realização multimodal da sinalização em Libras pode ser exemplificada a partir dos enunciados compostos apresentados na Figura 1. 


\section{REVISTA DA ABRALIN}

\begin{tabular}{|c|c|c|}
\hline Ocorrência & $\begin{array}{c}\text { Instanciação } \\
\text { Modal }\end{array}$ & Expressão \\
\hline & $\begin{array}{c}\text { Vocalização na } \\
\text { língua portuguesa }\end{array}$ & $\begin{array}{l}\text { Expressão } \\
\text { "Sabe?" }\end{array}$ \\
\hline & Instanciação manual & $\begin{array}{l}\text { Sinal } \\
\text { SABER }\end{array}$ \\
\hline (A) & Expressão facial & $\begin{array}{l}\text { Cenho franzido } \\
\text { significando } \\
\text { interrogativa } \\
\text { do tipo "sim/não" }\end{array}$ \\
\hline & $\begin{array}{c}\text { Bochechas infladas e } \\
\text { abertura súbita } \\
\text { da boca }\end{array}$ & $\begin{array}{l}\text { Onomatopeia } \\
\text { "pou" }\end{array}$ \\
\hline (B) & Instanciação manual & $\begin{array}{l}\text { Gesto representando } \\
\text { objeto caindo e } \\
\text { chocando-se contra o } \\
\text { chão }\end{array}$ \\
\hline
\end{tabular}

FIGURA 1 - Instanciações de enunciados multimodais em Libras Fonte: UFSC (2014)

A imagem (A) é um recorte de um enunciado no qual o sinalizante pergunta se o interlocutor sabe a que fruta ele está se referindo e, para elaborar a sinalização, faz uso das instanciações apresentadas, inclusive gestos bucais que se aproximam da palavra "sabe" em língua portuguesa. A imagem (B) é um recorte de um enunciado no qual o sinalizante estava demonstrando a queda das peras $\mathrm{e}$, junto à instanciação manual representando essa queda, o narrador emite sons onomatopeicos do impacto. Trata-se, portanto, de instanciações modais vocais, faciais e manuais que coocorrem na sinalização - ou seja, são um exemplo de cofala similar àquele oferecido por Müller (2019) no caso de referência ao tamanho das caixas, mas agora no contexto de uma língua sinalizada.

McCleary e Viotti (2017) defendem a multimodalidade da comunicação humana a partir da compreensão de que o corpo é o que possibilita a interação social e é a base para a emergência das próprias línguas humanas. Por isso, ancorando-se em Cadoz (1994), os autores concebem o "gesto como um dos canais de comunicação, ao lado da voz, da audição e da visão, cada um caracterizado por diferentes especificidades" (p. 5) e que assumem diferentes funções:

uma função epistêmica (quando, por exemplo, a mão serve como órgão de percepção), uma função ergótica (a mão como órgão de ação) e uma função semiótica (a mão como órgão de expressão) [...]. Essas 


\section{REVISTA DA ABRALIN}

funções não são excludentes, podendo um mesmo gesto servir a mais de uma delas. (MCCLEARY; VIOTTI, 2017, p. 5)

Tomando essa mesma perspectiva multimodal, Müller (2019) propõe um processo gradiente de lexicalização nas línguas de sinais. Tal como apresentado na Figura 2, cuja seta representa a mudança que ocorre ao longo do tempo, tanto as unidades gestuais quanto as pantomimas icônicas podem tornar-se cada vez mais estáveis, até o ponto em que se constituem como itens lexicais das línguas de sinais.

iconic pantomime gestural units not lexicalized signs

lexicalized

Esse processo de lexicalização, segundo Müller (2019), é marcado por uma mudança diacrônica, partindo de formas de gestos espontâneos em direção às formas mais padronizadas e arbitrárias (i.e. os "sinais"). Entre esses dois pontos, ela destaca a presença do que chama de "gestos semelhantes a sinais" (sign-like gestures) e "sinais gestuais" (gesture signs), considerados como formas intermediárias entre os gestos espontâneos e os sinais convencionalizados. A Figura 3 ilustra esse processo por meio do qual o sistema linguístico das línguas de sinais incorpora gestos e pantomimas. Devido à simplificação e à economia de ação manual que se dá nesse processo, os sinais tornam-se mais reduzidos em termos de iconicidade e, consequentemente, a sua forma se torna mais opaca.

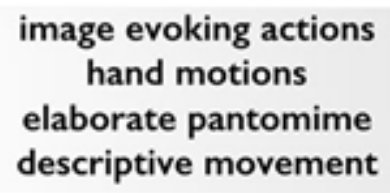

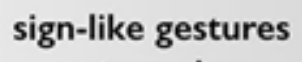

arbitrary form, signs, other gestures in the system

FIGURA 3 - Fases do desenvolvimento histórico

Fonte: Müller (2019, p. 33)

Por meio das Figuras 2 e 3, depreendemos que, para a autora, representações gestuais pictóricas se transformam em elementos arbitrários. A respeito desse processo de transformação do gesto em 


\section{REVISTA DA ABRALIN}

sinal, ela diz ser necessário que haja uma interação contínua em uma dada comunidade de fala para que os sinais estáveis se desenvolvam e que, na transformação de gestos espontâneos para sinais convencionais, alguns traços serão retidos à medida que contrastem com outros traços de uma dada língua de sinais.

Nessa reflexão, a linguista afirma ter se inspirado no continuum elaborado por McNeill (2000) para propor o seu contínuo, destacando que as formas discriminadas ao longo do espectro não são nitidamente separadas umas das outras como categorias discretas, mas sim arranjadas de modo gradiente. Para a autora, os critérios de convencionalização, composicionalidade e relação forma-significado constituem aspectos dinâmicos que subjazem à transformação de gestos em sinais. As Figuras 4 e 5 apresentam o contínuo proposto por McNeill (2000) e a adaptação feita por Müller (2019):

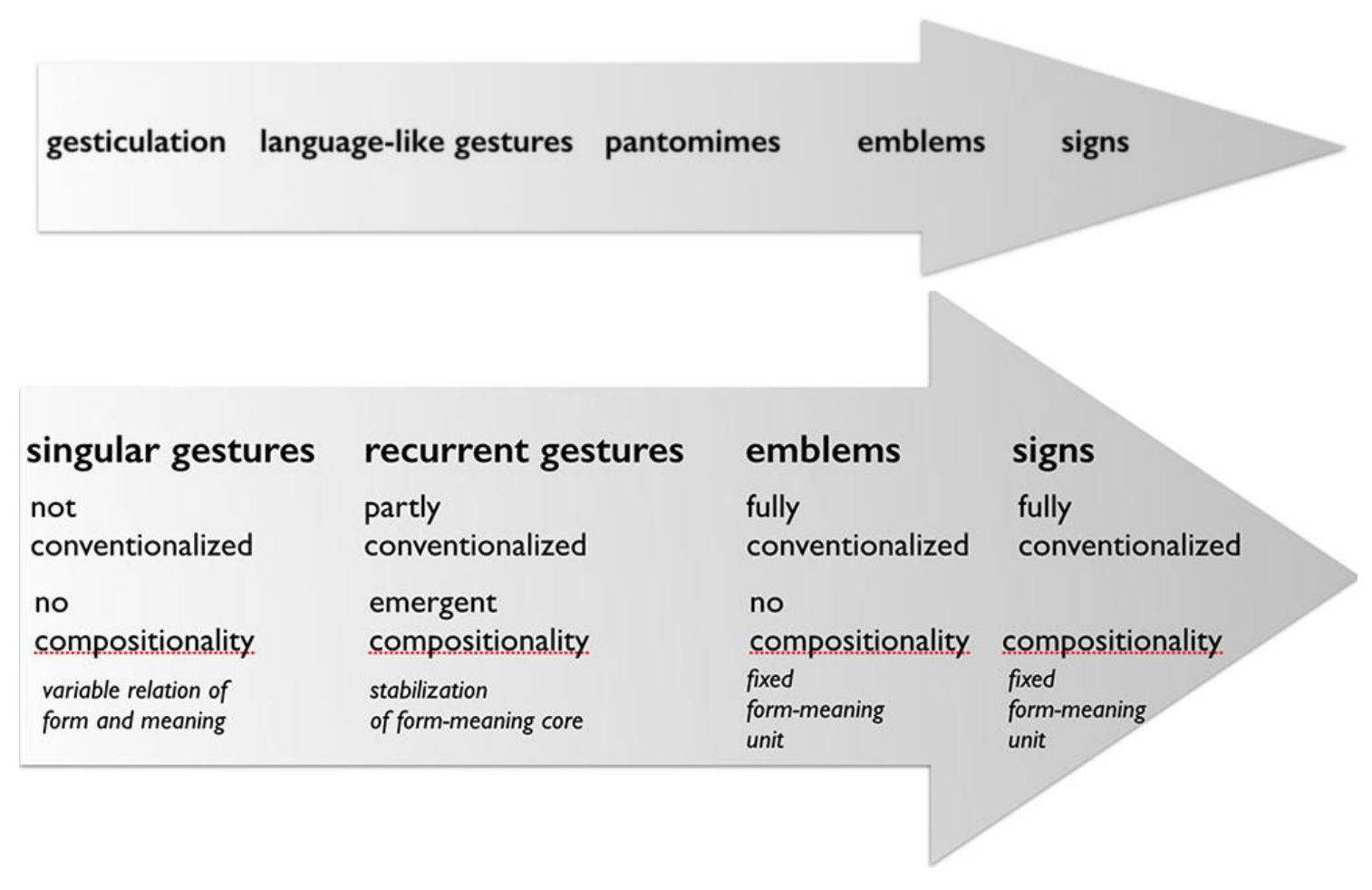

FIGURA 4 - Contínuo elaborado por McNeill (2000) e a adaptação de Müller (2019) Fonte: Müller (2019, p. 42)

Müller (2019) assim explica os quatro diferentes pontos norteadores do contínuo:

- os gestos singulares são gesticulações espontâneas ad-hoc e incluem formas pictóricas e pantomímicas. São considerados gestos não convencionalizados e apresentam uma relação variável de forma e significado que depende de cada situação comunicativa; 


\section{REVISTA DA ABRALIN}

- os gestos recorrentes são gestos em que todos os parâmetros (convencionalidade, composicionalidade e relação forma-significado) são emergentes, tais como as "famílias de gesto" estudadas por Kendon (2004) ${ }^{1}$ (MÜLLER, 2019, p. 33);

- os emblemas são gestos convencionalizados que adquirem significados estáveis, embora não sejam decomponíveis em unidades menores, e podem ser usados como substitutos para palavras nas línguas orais em alguns contextos;

- por fim, os sinais são gestos que apresentam todas as propriedades linguísticas identificadas para as línguas naturais: são convencionais, decomponíveis em unidades menores que integram um sistema de contrastes e com relações estáveis entre forma e significado.

Para Müller, os gestos também se distinguem quanto às funções linguísticas e comunicativas. Em relação a isso, a autora explica que:

- os gestos singulares são criados localmente e, embora sejam baseados em um repertório culturalmente compartilhado de técnicas de criação, as realizações específicas em um determinado contexto são livres e espontâneas. Eles apresentam principalmente funções lexicais, como apresentando atributos visuais referentes a itens lexicais com os quais coocorrem. Desse modo, operam juntamente com as expressões verbais das línguas orais, contribuindo com elas semanticamente ou metacomunicativamente;

- os gestos recorrentes servem principalmente às funções pragmáticas, estando associados implícita ou explicitamente a determinados contextos pragmáticos, mais do que a conteúdos semânticos específicos;

- os emblemas realizam atos de fala completos, como o conhecido o "gesto de ok", que pode ser entendido como um ato de fala "está tudo bem" ou "foi ótimo", por exemplo. Esses atos de fala gestuais podem vir acompanhados por expressões verbais, mas não raro eles são usados para substituir palavras nas línguas orais.

Müller (2019) afirma que as mudanças históricas ocorrem de forma gradual e dinâmica a partir de acordos tácitos de uma comunidade a respeito das formas e funções gestuais que

\footnotetext{
${ }^{1}$ Kendon (2004) introduz alguns exemplos de "famílias de gestos", como o chamado palm-up gesture, ou gesto com a palma virada para cima. Dentro dessa configuração geral, diferentes tipos de gesto podem ser realizados com nuances de sentido similares. Nesse caso, as diferentes formas de palm-up gesture têm sido associadas a contextos em que o falante está oferecendo, dando ou mostrando alguma coisa ou, ainda, solicitando que algo seja recebido pelo interlocutor. Retornaremos à discussão sobre o gesto palmup mais adiante.
} 


\section{REVISTA DA ABRALIN}

emergem do uso da linguagem e mudam com ele. Tais mudanças é que levam algumas formas gestuais a se estabilizarem por meio de usos repetidos e, em alguns casos, passarem pela lexicalização e se transformarem em sinais, sendo que o desenvolvimento histórico do gesto para o sinal pode ter início com qualquer um desses três tipos de gestos (singular, recorrente ou emblema) ao longo do continuum. Essa é uma questão um pouco problemática, pois o continuum sugere que sinais resultam de lexicalizações de emblemas; entretanto, isso não ocorre em grande parte dos casos.

Um aspecto importante destacado por Müller (2019) sobre esse continuum é que, para a autora, ele serve tanto para línguas orais quanto para línguas de sinais. Por isso, ela aborda brevemente a questão da comparação interlinguística entre línguas orais e línguas de sinais. Ainda, a pesquisadora sustenta que também há uma semelhança entre as línguas orais e de sinais no que diz respeito ao uso de gestos, assim como para Kendon (2004), cujo estudo compara o "uso do espaço" por falantes de línguas orais e línguas de sinais e aponta para uma exploração similar do espaço: primeiro eles configuram uma cena espacialmente e, em seguida, apontam anaforicamente para onde os referentes foram previamente localizados. Outro aspecto indicado por Müller (2019) relaciona-se às realizações conhecidas nas línguas de sinais como "classificadores", que apresentam muita semelhança com produções gestuais de falantes de línguas orais. Um último exemplo trazido dessas semelhanças no uso de gestos nas línguas orais e línguas de sinais é o emprego da chamada "ação construída" (LIDDELL; METZGER, 1998), que envolve enunciados em que os falantes demonstram iconicamente com o seu corpo de que modo uma dada ação foi realizada. Com base nessa reflexões, Müller (2019) afirma compartilhar da visão de Kendon (2004), segundo o qual "os usos de ações cinésicas por parte dos falantes de línguas orais e os usos de ações cinésicas por parte dos falantes de línguas de sinais são produzidos a partir do mesmo material" (KENDON, 2004, p. 324 apud MÜLLER, 2019, p. 33, tradução nossa).

Essas semelhanças no uso de gestos entre as línguas orais e línguas de sinais não acontecem apenas por conta de o meio de expressão (as mãos e o resto do corpo) ser comum a ambas, mas também devido ao fato de que as línguas orais e sinalizadas estão em permanente contato. Por esse motivo, como ilustrado na Figura 5, a autora defende a ideia de que os três tipos de gestos descritos anteriormente coocorrem tanto com as palavras das línguas orais quanto com os sinais das línguas sinalizadas.

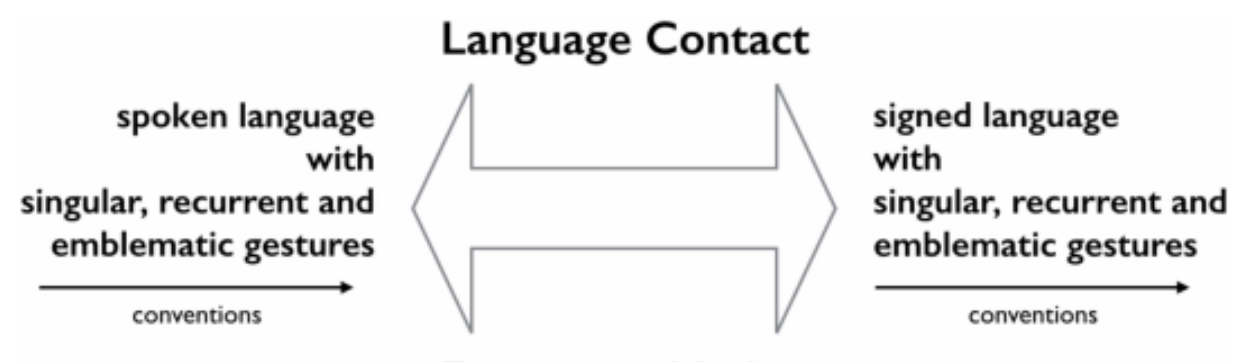

\section{Expressive Medium}




\section{REVISTA DA ABRALIN}

Em suma, em seu trabalho, Müller (2019) se alinha à perspectiva de Kendon (2004) de que exista uma continuidade entre os gestos e os sinais, em vez de uma "ruptura cataclísmica", como propõem Goldin-Meadow (2015) e Goldin-Meadow e Brentari (2017). Com base no contínuo de McNeill (2000), Müller (2019) elabora então uma nova proposta identificando diferentes "pontos" do espectro gestual de acordo com três critérios: convencionalização, composicionalidade e relação forma-significado. O Quadro 1 representa visualmente os critérios que caracterizam os diferentes pontos no contínuo de Müller (2019):

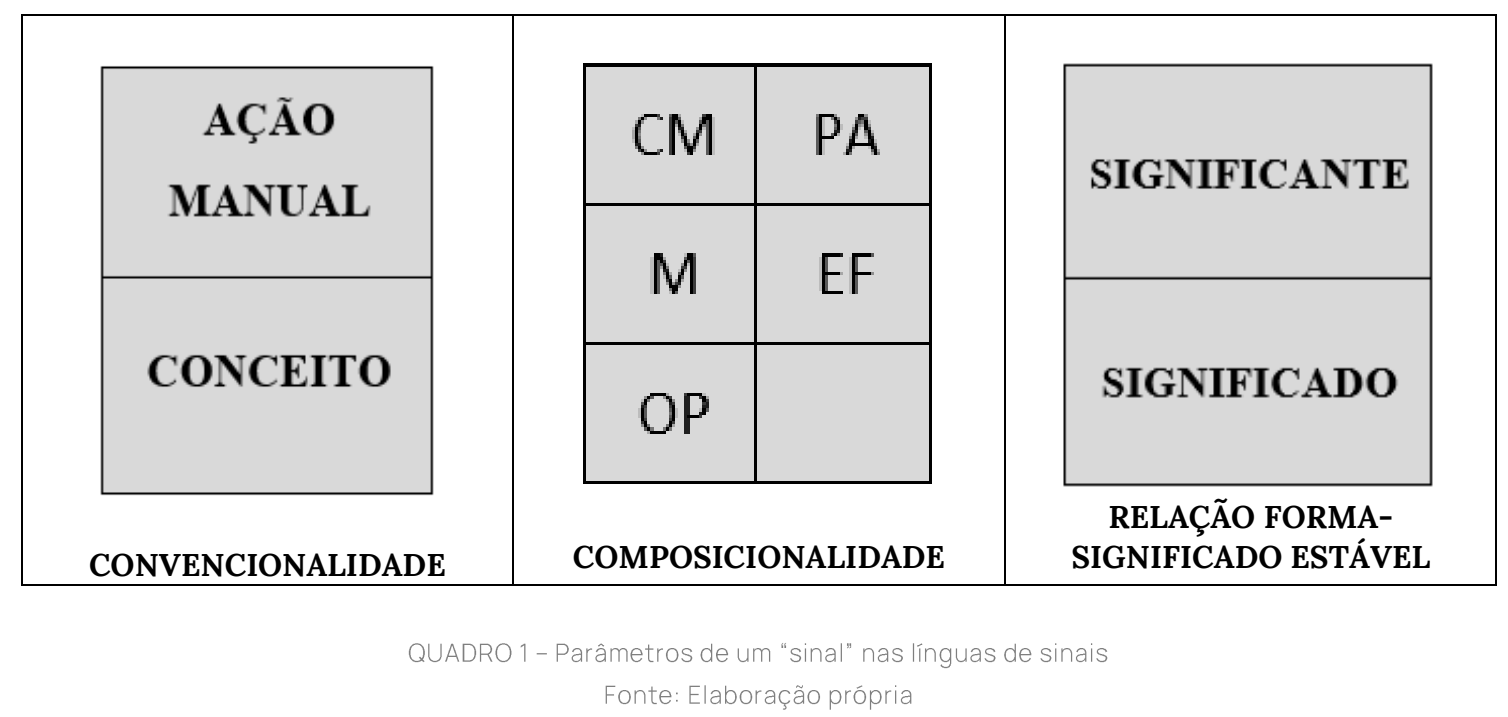

Nos sinais, os parâmetros linguísticos de convencionalidade, composicionalidade e a relação forma-significado são estáveis. Os signos que são formados pelas unidades mínimas CM (configuração de mão), M (movimento), PA (ponto de articulação), EF (expressão facial) e OP (orientação da palma) entram em um sistema linguístico de contrastes (sintagmático e paradigmático). Já nos emblemas, conforme representa o Quadro 2, a convencionalidade e a relação de forma-significado estão estabelecidos, mas ainda não a composicionalidade ${ }^{2}$ :

\footnotetext{
${ }^{2}$ Essa conceitualização não reflete a visão do autor, pois empiricamente se verifica que alguns emblemas apresentam contraste em suas formas.
} 


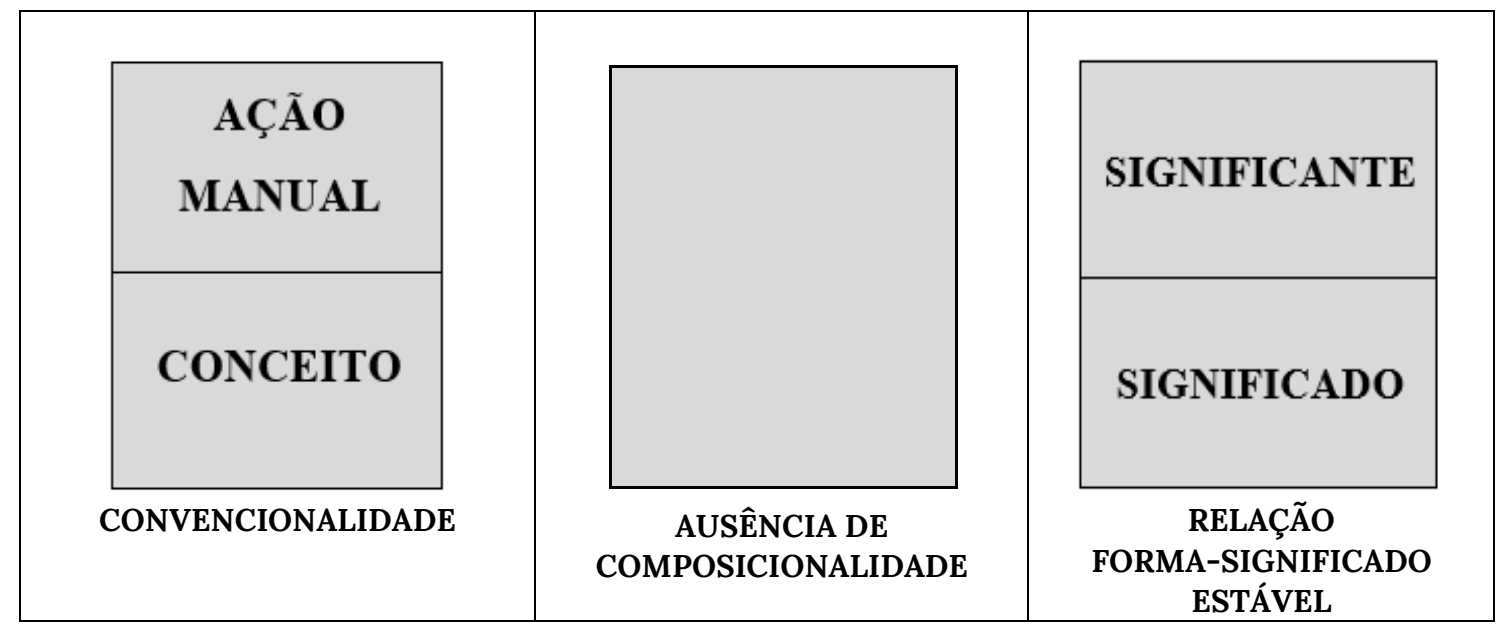

QUADRO 2 - Ilustração do conceito de emblema a partir da definição de Müller (2019)

Fonte: Elaboração própria

Nos gestos recorrentes, as três propriedades linguísticas podem estar em processo de emergência (Quadro 3):

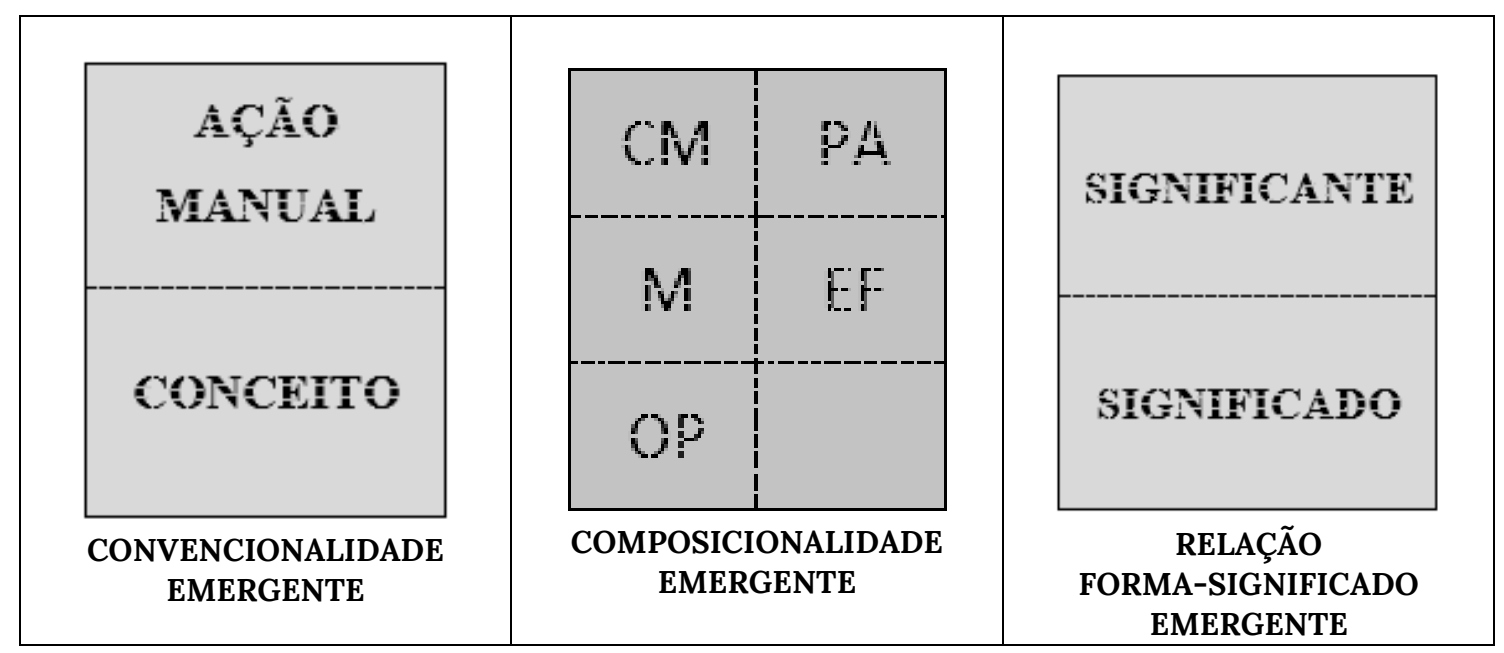

QUADRO 3 - Ilustração do conceito de gestos recorrentes

Fonte: Elaboração própria

Por fim, o Quadro 4 mostra que os gestos singulares são aqueles específicos de cada situação; portanto, são não convencionais, não composicionais e sem relação estável entre forma e significado: 


\section{REVISTA DA ABRALIN}

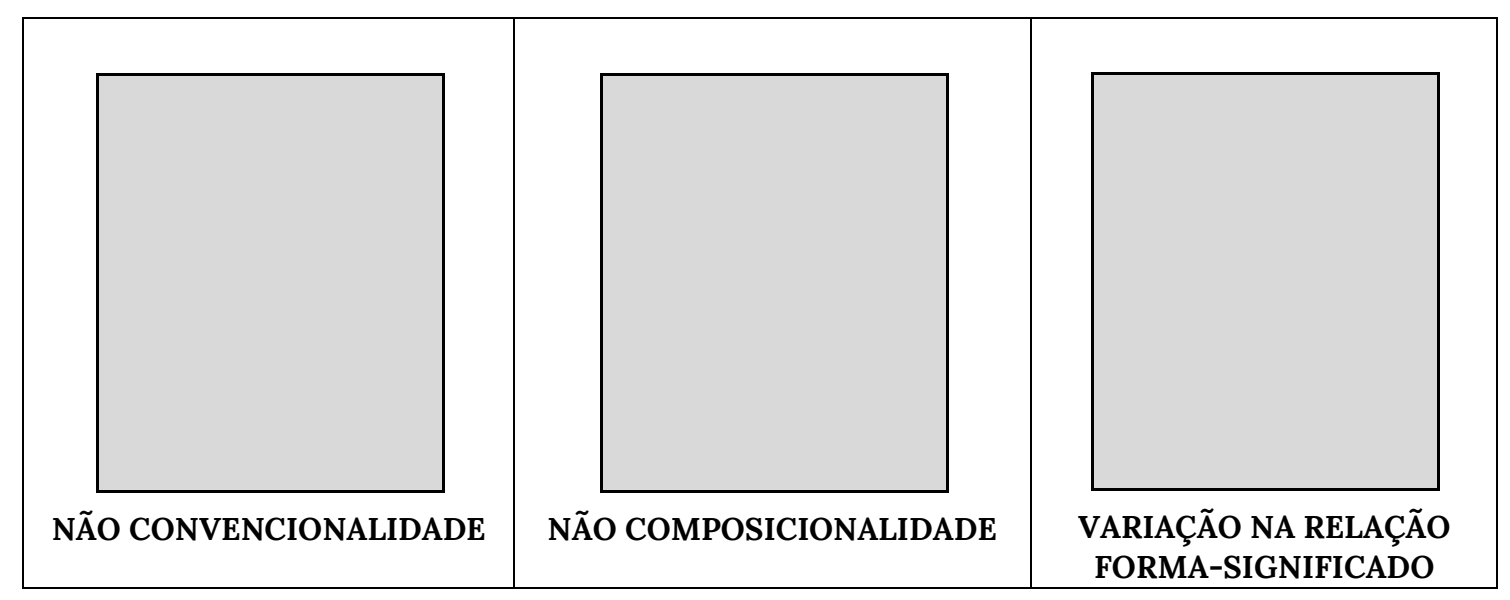

QUADRO 4 - Ilustração do conceito de gestos singulares

Fonte: Elaboração própria

Sendo assim, apresentamos a seguir os procedimentos da geração, tratamento e análise dos dados de Libras que serviram para descrição e análise buscando verificar a proposta de Müller (2019).

\section{Metodologia}

Com base no referencial teórico delineado, buscamos aplicar a perspectiva de Müller (2019) na análise de narrativas em Libras, de modo a explorar a sua adequação empírica, particularmente considerando-se que a autora não apresenta análise de dados referentes a línguas de sinais em seu trabalho. Em específico, esta análise será feita com foco nos quatro pontos de seu contínuo gestual, a fim de verificar em que medida esses marcos se aplicam em Libras.

As duas narrativas aqui analisadas foram retiradas no Corpus Libras (UFSC, 2014), no qual há registros em vídeos de uso da Libras eliciados e semiespontâneos. Dentre as opções disponíveis, foi escolhida a narrativa da história da pera, coletada por meio de um filme sem linguagem verbal com, aproximadamente, seis minutos de duração. Após assistir ao vídeo (PEARFILM, 2008), o participante surdo reconta a narrativa em Libras para um interlocutor surdo.

De forma sucinta, trata-se da história de um homem que está colhendo peras na árvore e não percebe a presença de um menino que chega de bicicleta e rouba uma de suas cestas cheias de frutas. O menino pega a cesta, coloca-a na bicicleta e sai pedalando até que vê uma menina vindo de bicicleta em sua direção, distrai-se, bate em uma pedra e cai, derrubando as peras no chão. Três outros meninos o ajudam e recebem, cada um deles, uma pera como recompensa. Ao saírem passeando e comendo suas peras, eles passam pelo homem agricultor, que acabara de perceber a falta da cesta. Ele os observa com desconfiança, e a história termina.

O Corpus de Libras conta com uma grande quantidade de vídeos organizados em categorias e em narrativas, encontra-se 18 vezes a história da pera. Isso porque os sinalizantes foram filmados em (18) duplas, e apenas 1 sinalizou essa narrativa. Os nomes dos 36 participantes estão disponíveis 


\section{REVISTA DA ABRALIN}

na plataforma e, por conhecê-los da comunidade surda, foram escolhidos o Jusélio, um sinalizante fluente em Libras, e o Edson, que faz uso de sinais caseiros. Cada uma das narrativas analisadas tem, em média, 3 min $15 \mathrm{~s}$ de duração.

Os dados foram visualizados no programa MOVAVI, um software de edição que permite que os frames do vídeo sejam extraídos em formato de imagem para serem reproduzidos neste artigo. Em seguida, procurou-se uma correlação entre as ações manuais identificadas e as estruturas descritas no continuum elaborado por Müller (2019); em específico, foram buscados os traços de convencionalidade, composicionalidade e relação forma-significado em cada uma das ações manuais apresentadas na narrativa. A análise descritiva e interpretativista também investigou evidências de ações manuais que se situariam entre um ponto e outro ou até se não se encaixariam na proposta da autora. A pesquisa é descritiva porque, como afirmam Gerhardt e Silveira (2009), visa a descrever as características do fenômeno em questão - no nosso caso, as ações manuais em Libras -, e é também interpretativa porque busca relacionar essa descrição com a perspectiva teórica de Müller (2019).

\section{Descrição e interpretação dos dados}

Quando Müller (2019) sintetiza sua discussão e afirma que tanto as palavras das línguas orais quanto os sinais das línguas de sinais coocorrem com gestos singulares, recorrentes e emblemáticos, coloca-se para o pesquisador de línguas de sinais o desafio de identificar o funcionamento desse contínuo em Libras. Nesse sentido, um ponto importante de ser esclarecido é o de que, embora seja equivocado interpretar os quatro pontos do contínuo (i.e. gesto singular, recorrente, emblemático e sinal) como "categorias" discretas, já que se trata de um fenômeno gradiente, ainda assim podemos considerá-los como pontos de ação manual prototípicos (LAKOFF, 1987), e é nesse sentido que nesta análise saímos em busca de ações manuais que possam (ou não) corresponder a esses pontos. Na análise de aproximadamente 70 ações manuais de cada sinalizante, 65 foram passíveis de classificação. As que não foram classificáveis serão apresentadas na seção 3.2.

\subsection{Ações manuais que convergem no contínuo de Müller (2019)}

Ao longo de uma narrativa, encontramos 55 ações manuais que apresentam todas as propriedades linguísticas identificadas para as línguas naturais: são convencionais, decomponíveis em unidades menores que se estabelecem em um sistema de contrastes e com relações fixas entre forma e significado e, portanto, de acordo com Müller (2019), seriam classificadas no ponto dos "sinais". Dentre essas, destacamos o exemplo da Figura 6: 


\section{REVISTA DA ABRALIN}

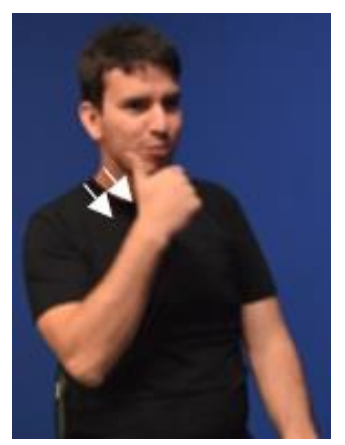

FIGURA 6 - Exemplo do sinal GÊNERO-FEMININO na narrativa em Libras Fonte: UFSC (2014)

A ação manual demonstrada na Figura 6 é um sinal convencionalizado na comunidade surda brasileira usuária de Libras. O signo (significado e significante) é específico dessa língua e, por esse motivo, falantes de outras línguas de sinais podem não o decodificar, já que não compõem o conjunto lexical do seu idioma. Esse sinal se realiza por meio da composição de unidades menores, quais sejam: a mão configurada com dedo polegar estendido (CM) e com a palma orientada para dentro (OP) toca a lateral do rosto (PA) e produz dois movimentos (M) retos para baixo. É esse conjunto de unidades que forma o significado para "gênero feminino" e, se houver uma alteração em um dos seus segmentos, surge um novo item lexical. É o caso da alteração do PA para o centro do queixo, que modifica o item lexical passando a significar "fluxo menstrual". Esses dois sinais constituem pares mínimos e apresentam contraste em apenas um dos seus parâmetros (PA), demonstrando tratar-se de uma ação manual decomponível. Assim, o signo GÊNERO-FEMININO em Libras é uma ação manual convencional, decomponível e com relação significante-significado estável.

Diferentemente dos sinais, de acordo com Müller (2019), os emblemas não fazem parte de um sistema linguístico; porém, dada a convencionalidade em determinada comunidade, adquirem significados estáveis, embora não sejam decomponíveis em unidades menores. Em alguns contextos, essas ações manuais podem ser usadas como substitutos para palavras nas línguas orais. Ao longo da narrativa, encontramos sete ações manuais que parecem atender aos critérios de um emblema, e a Figura 7 ilustra uma delas:
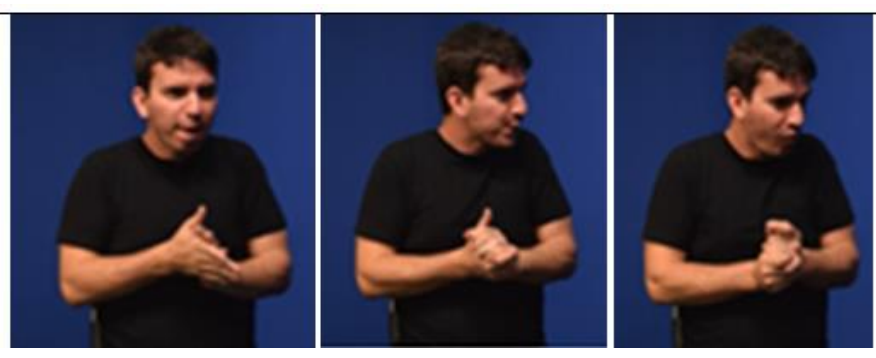

FIGURA 7 - Possivel exemplo de emblema na narrativa em Libras Fonte: UFSC (2014) 


\section{REVISTA DA ABRALIN}

A Figura 7 mostra a ação manual realizada pelo sinalizante para referir-se à ação do menino que roubou as peras. Essa ação manual é uma forma convencional que encontramos no discurso de falantes de Libras e de português, e a sua forma e o seu significado também parecem ter uma relação estável ligada à expectativa e excitação diante de algo que vai ocorrer - e, acompanhada da expressão na Figura 7, também ligada a uma ação de traquinagem. Entretanto, o emblema não é composicional, haja vista que as variações do movimento de esfregar uma mão na outra não se comportam de forma estável como ocorre com itens lexicais das línguas de sinais. Portanto, sobre ele recai uma análise holística em detrimento de um segmental.

Considerando ainda que para Müller (2019) a lexicalização nas línguas de sinais é um processo gradiente através do qual a mudança ocorre ao longo do tempo, podemos argumentar que o sinal ANSIEDADE em Libras seria uma possível exemplificação de lexicalização desse emblema em Libras, em que a forma do sinal se adequa à condição de simetria (ambas as mãos apresentam a mesma configuração e disposição especulares) e ganha um significado lexical estável, ligado à "ansiedade" e "expectativa". Ou seja, poderíamos hipotetizar que o emblema da Figura 7 evoluiu em Libras para a forma padronizada e arbitrária que constituiu o item lexical ilustrado na Figura 8.

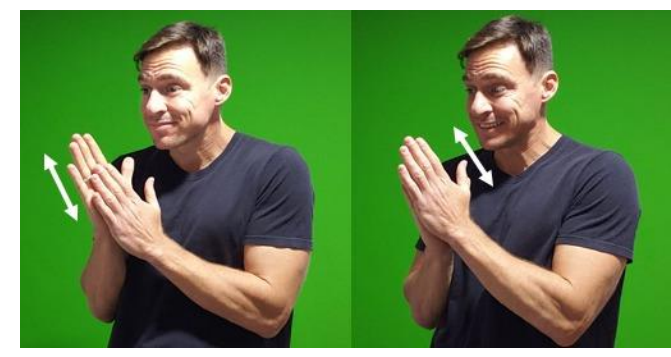

FIGURA 8 - Sinal de ANSIEDADE em Libras

Fonte: Arquivo pessoal

Além dos possíveis emblemas que identificamos, três ações manuais nos pareceram adequar-se às características dos gestos recorrentes estipulados por Müller (2019). Uma delas é apresentada na Figura 9: os gestos do tipo palm-up. Em (A), o sinalizante incorporou a expressão de dúvida do homem agricultor que procurava a cesta que havia sumido e, no caso de (B), o sinalizante incorporou a expressão de frustação do menino que derrubou as peras no chão. 


\section{REVISTA DA ABRALIN}

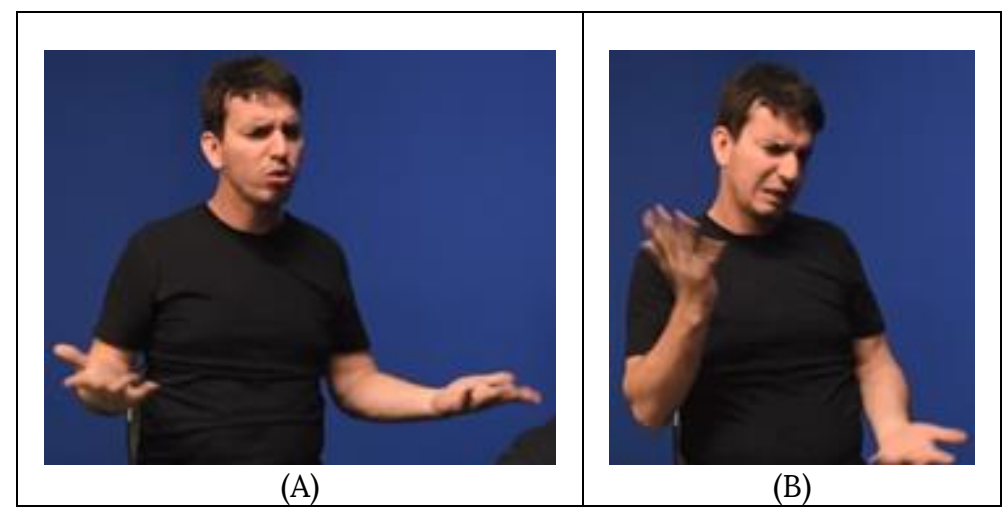

FIGURA 9 - Possíveis exemplos de gestos recorrentes na narrativa em Libras Fonte: UFSC (2014)

A palma para cima, segundo Müller (2019), é utilizada pelos ouvintes falantes de alemão e pelos surdos sinalizantes da língua de sinais alemã (DGS). De acordo com Cooperrider, Abner e GoldinMeadow (2019), essa forma de gesto já foi amplamente pesquisada em inúmeras línguas orais, entre as quais árabe, catalão, alemão, inglês, francês, italiano, português, suaíli e zulu. O palm-up já foi estudado também em várias línguas de sinais pelo mundo, tais como língua de sinais americana, língua de sinais neozelandesa, língua de sinais turca, holandesa, israelita, sueca, indiana, alemã e indo-paquistanesa (COOPERRIDER; ABNER; GOLDIN-MEADOW, 2019). Nesses estudos, o entendimento é de que a produção tem a função de um "gesto epistêmico", que expressa pragmaticamente a noção de "não saber ou não entender alguma coisa", e por vezes o gesto é acompanhado por um encolher de ombros e expressão facial, quando se aproxima da noção de um gesto emblemático, que significaria algo como "não posso fazer nada".

Essa ação manual é considerada gesto recorrente, pois todos os parâmetros (convencionalidade, composicionalidade e relação forma-significado) são emergentes (MÜLLER, 2019) e, portanto, podem passar por transformações que levem à sua lexicalização. Nesse sentido, gostaria de propor que esse gesto, de fato, já passou por processos de lexicalização que pude identificar tanto em Libras quanto na língua de sinais americana, nos sinais QUAL e O-QUE, observados em Libras e na língua de sinais americana, respectivamente. Os itens lexicais que supostamente derivaram desses gestos recorrentes estabilizaram o movimento das mãos, que no caso de (A) envolve uma mudança semicircular da OP de baixo para cima e, no de (B), dois movimentos curtos retilíneos para os lados. Os dois sinais são ilustrados na Figura 10 e aparecem em contextos de sentenças interrogativas como, "Qual cor você prefere?" (A) e "Você trabalha no quê?" (B). 


\section{REVISTA DA ABRALIN}

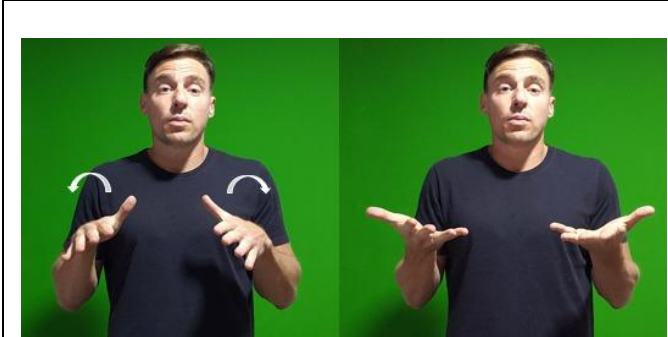

(A)

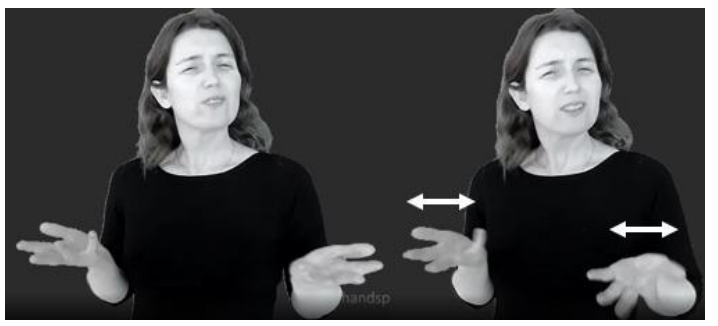

(B)

FIGURA 10 - Sinal de QUAL em Libras e O QUE na língua americana de sinais Fonte: (A) Arquivo pessoal e (B) Sign Language Online

Por fim, a narrativa sinalizada por outro participante surdo apresenta ações manuais que nos parecem adequar-se às caraterísticas do que Müller (2019) chama de gestos singulares (Figura 11).

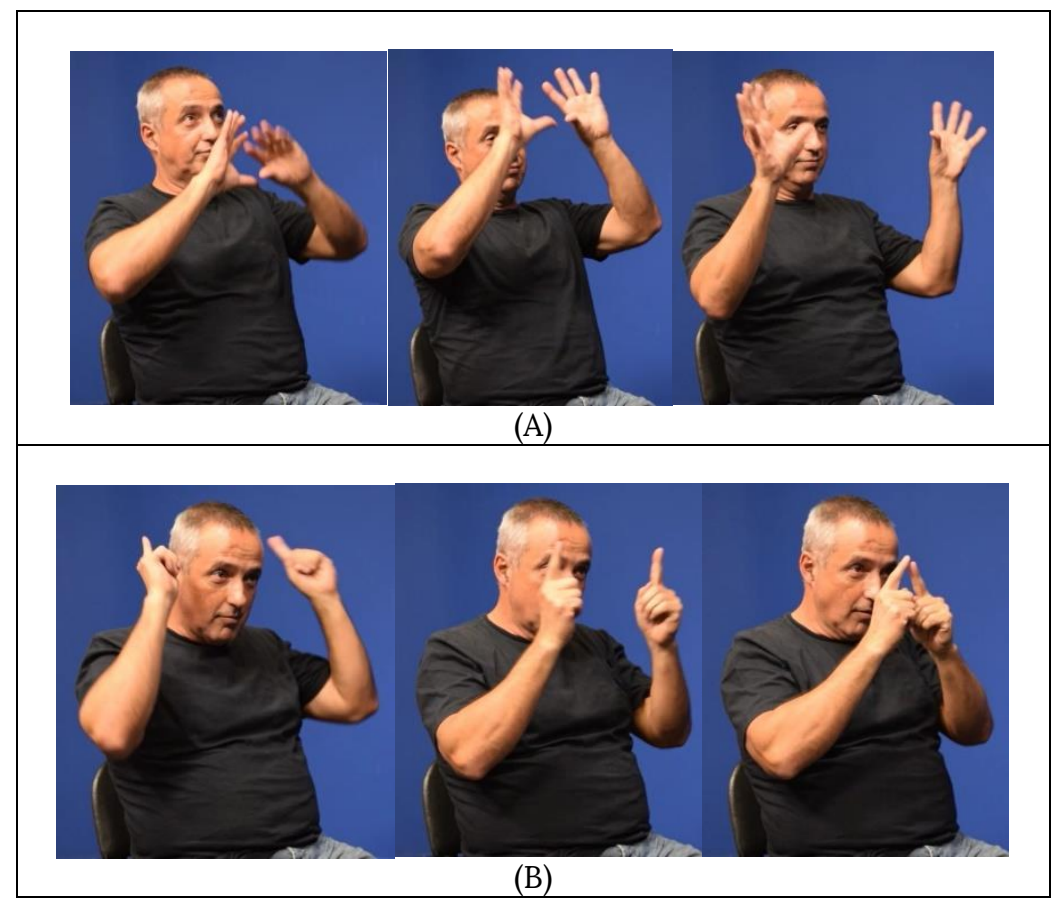

FIGURA 11 - Possiveis exemplos de gestos singulares na narrativa em Libras Fonte: UFSC (2014)

Essas duas realizações parecem ser gestos que envolvem formas pictóricas, não convencionalizadas e com uma relação entre forma e significado dependente do contexto em que foram produzidas. As imagens (A) e (B) são difíceis de serem interpretadas sem se conhecer o contexto da enunciação. Tendo acesso à narrativa completa, podemos compreender que, pelo uso do gesto demonstrado na imagem (A), o sinalizante está fazendo menção ao formato da copa das árvores, enquanto em (B) ele está se referindo ao formato do chapéu do homem agricultor. Contudo, essa depreensão é possível apenas para quem conhece a história que está sendo narrada; em outras narrativas, os 


\section{REVISTA DA ABRALIN}

narradores surdos usaram outras CMs, outros $\mathrm{M}$ e outras OPs para representar o mesmo formato do chapéu da história original da pera.

\subsection{Ações manuais que levantam questões sobre o contínuo de Müller (2019)}

Um problema que identificamos na proposta de Müller (2019) é que aquilo que no contexto de línguas orais facilmente seria classificável no ponto dos emblemas, no caso das línguas de sinais, parece ser melhor classificável como estando no ponto dos sinais. Isso porque, segundo Kendon, os emblemas são convencionais e se parecem com as palavras por respeitarem a condições de boa formação, terem significado mais ou menos estável e poderem, inclusive, ser usados sem a fala. Ilustramos essa problemática com a ação manual da Figura 12.

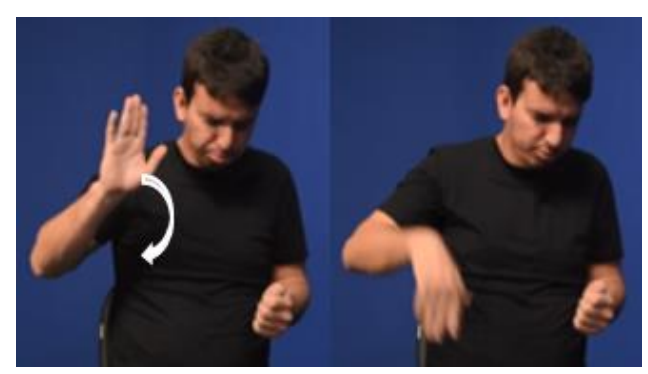

FIGURA 12 - Ação manual que levanta questões sobre o contínuo de Müller (2019) Fonte: UFSC (2014)

Em um contexto do português, por exemplo, a ação manual ilustrada certamente seria identificada como um emblema, pois se trata de um gesto convencional e com uma relação forma-significado estável, traduzível por expressões tais como "deixa pra lá!", "não dei bola!", "não tô nem aí!". Porém, ela não integra um sistema de contraste com outros gestos manuais, possivelmente pelo fato de que nas línguas orais a ação manual emerge como pano de fundo para a expressão verbal e, portanto, não apresenta o caráter decomponível.

Entretanto, quando olhamos sob a ótica de uma língua sinalizada como a Libras, essa mesma ação manual - ainda que compartilhe com o português as mesmas características de convencionalidade e relação forma-significado estável - também demonstra segmentabilidade. Por exemplo, podemos decompor esse sinal, que glosaremos como DEIXA-PRA-LÁ, com base nos parâmetros CM (palma aberta), PA (espaço lateral do tronco), M (semicircular de cima para baixo), EF (lábios para fora) e OP (de baixo para a direção do tronco), e perceberemos que ele contrasta com um par mínimo, o sinal MAIS, que se distingue precisamente pelo M contrário, de baixo para cima (Figura 13). 


\section{REVISTA DA ABRALIN}

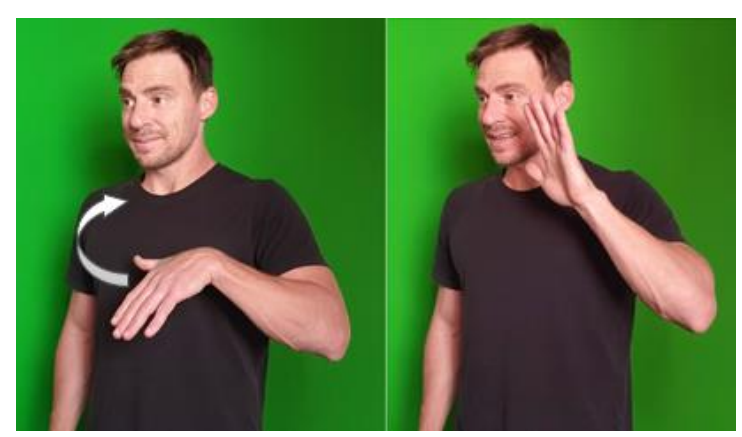

FIGURA 13 - Sinal de MAIS em Libras

Fonte: Arquivo pessoal

Essa mesma ação manual também é usada por ouvintes com sentidos de "xô" (sai daqui) e, se repetida, pode indicar instruções para o motorista ir mais para frente. Nesse sentido, precisaríamos considerar que exatamente a mesma ação manual, quando produzida no contexto de uma língua oral, pode ser categorizada como um emblema; no entanto, quando produzida no contexto de uma língua sinalizada, pode ganhar o estatuto de sinal. Uma possível explicação para esse fenômeno seria a de que os emblemas compartilhados entre as comunidades de surdos e ouvintes tendem, nas línguas sinalizadas, a sofrer pressão para integrar um sistema de contrastes e tornarem-se lexicalizados.

Outro fenômeno que levantou questões acerca do contínuo gestual de Müller (2019) são as ações manuais com funções discursivas, em particular as boias. Silva (2014) explica que, de acordo com Liddell (2003):

\footnotetext{
as boias são frutos da integração conceitual entre entidades conceituais do discurso e a mão passiva sustentada em uma determinada configuração enquanto a mão ativa continua produzindo sinais. Uma vez realizadas, as boias se tornam instâncias visíveis da entidade conceitual que a mão passiva representa, $\mathrm{e}$ servem para fazer referência a essas entidades (SILVA, 2014, p. 73).
}

O autor menciona os diferentes tipos de boias: boias depictivas, boias de listagem e fragmentos de boia. Para essa reflexão, abordaremos as boias de listagem encontradas na narrativa. Segundo Silva (2014, p. 73), as boias de listagem são aquelas "por meio das quais o sinalizador cria uma lista visível com os dedos da mão passiva, que, por sua vez, são relacionados, no discurso a certas entidades", tal como ilustrado na Figura 14. 


\section{REVISTA DA ABRALIN}

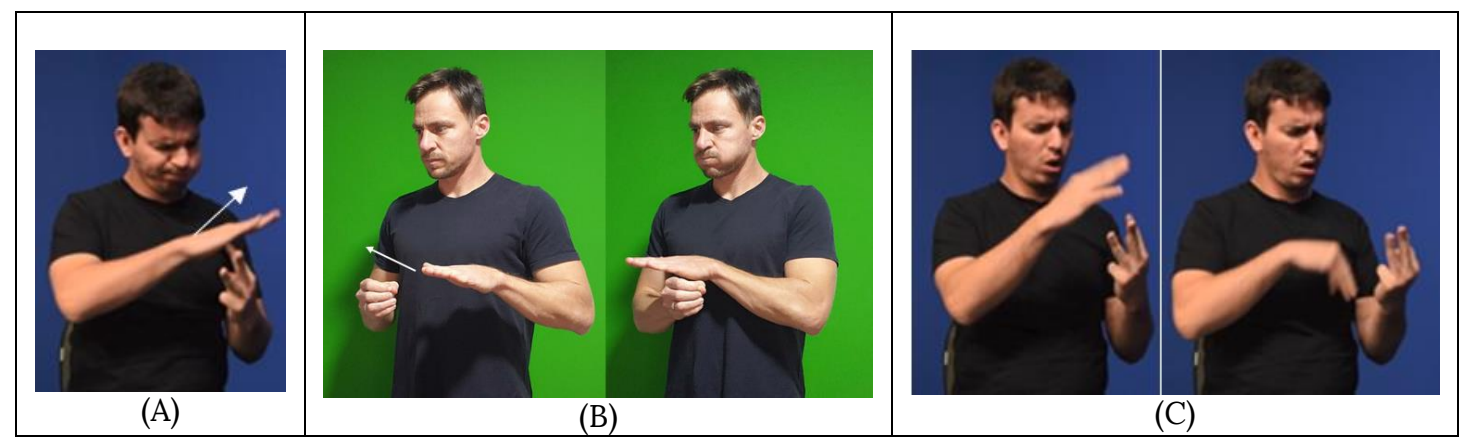

FIGURA 14 - Exemplos de boias de listagem na narrativa em Libras Fonte: UFSC (2014)

A listagem criada pelo sinalizante está demonstrada pela mão não dominante (que nesse caso foi a esquerda) e, discursivamente, recupera de modo anafórico as três cestas da história. Na imagem (A), a mão direita (ativa) realiza outro sinal de modo parcial, relativo ao sinal CHEI@. O sinal CHEI@, como mostra a imagem (B), é feito com a CM da mão direita passando por cima da mão esquerda em formato cilíndrico, acompanhado da bochecha inflada. Para transmitir a ideia de que as cestas estavam cheias, o sinalizante então empregou a mão dominante do sinal CHEI@ com CM, M, PA, ENM sem alterações; porém, em vez da mão passiva em formato cilíndrico, utilizou as boias que se referiam às "cestas".

A meu ver, esse tipo de ação manual desafia a classificação no contínuo, pois pela análise percebe-se que até mesmo os sinais convencionais, como CHEI@, podem ser localmente modificados em contextos específicos, o que parece assemelhar-se ao que ocorre com gestos singulares (HEITKOETTER; XAVIER, 2020).

Na nossa compreensão, ações manuais como expostas na imagem (A) da Figura 14 envolvem características tanto de gestos singulares (localmente criados e interpretados) quanto de sinais (convencionais e composicionais), portanto levantam questões em relação a uma aparente linearidade pressuposta no contínuo. Apesar de a construção feita pelo sinalizante respeitar alguns traços convencionais do sistema fonotático e morfossintático, também mantém traços de gestos singulares e é, então, uma interessante questão que merece ser investigada em profundidade em trabalhos futuros.

Já a imagem (C) da Figura 14 foi extraída de um excerto no qual, para transmitir a ideia de que uma das cestas cheias havia sumido, o sinalizante bateu no dedo indicador e o abaixou, enquanto manteve os dedos médio e anelar estendidos. Em princípio, poderíamos argumentar que as boias de listagem são convencionais, decomponíveis e com relação forma-significado estável, uma vez que refletem os itens "1, 2, 3..." de uma lista. Contudo, ao manipular a boia de listagem e rebaixar o dedo indicador, o resultado parece ser o de uma modificação do número de listagem DOIS, convencionalmente realizado com os dedos indicador e médio, para uma forma em que apenas os dedos médio e anelar ficam estendidos. Assim, ao mesmo tempo que a convencionalidade e a composicionalidade da boia de listagem parecem estar presentes, a sua forma-significado pode ser manipulada e modificada (gestual e linguisticamente) pelo sinalizador em certos contextos para desempenhar funções discursivas específicas. 


\section{REVISTA DA ABRALIN}

Por fim, as ações manuais produzidas em contexto de ação construída (LIDDELL; METZGER, 1998) também são um importante aspecto discursivo das línguas de sinais que tivemos dificuldade de situar no contínuo de Müller (2019), uma vez que apresenta diversas estratégias para demonstrar as camadas de significação da narrativa (MCCLEARY; VIOTTI, 2011).

McCleary e Viotti (2011) explicam que os espaços mentais ${ }^{3}$ são estruturas conceituais abstratas e dinâmicas através das quais compreendemos e expressamos as nossas experiências no mundo. Para expressarmos nossas experiências no mundo, interagimos face a face com o interlocutor real em um espaço real, ou seja, trata-se da existência de uma pessoa em carne e osso (os participantes surdos do Corpus Libras, por exemplo). Em uma narrativa, além do espaço conceitual do ser humano sinalizante, há o nível de intersubjetividade do mundo na narração, quando ele assume o papel de narrador para adentrar no domínio da história. Além disso, há uma terceira camada de significação, que é a caracterização de cada um dos personagens, realizada pela integração da figura do narrador com o autor. Em tal caracterização, os traços psicológicos, sociais, atitudinais e verbais dos personagens são apresentados a partir da integração conceitual que necessariamente envolve um corpo presente do autor durante a ação construída.

Nos nossos dados, em diversos momentos o sinalizante está operando dentro dessas três camadas de significação simultaneamente: como autor, narrador e personagem. A Figura 15 ilustra uma ocorrência dessa reflexão:

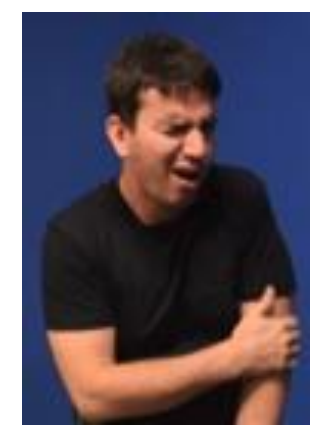

FIGURA 15 - Exemplo de ação construída na narrativa em Libras Fonte: UFSC (2014)

A ação construída demonstrada na Figura 15 se deu quando o autor-narrador-personagem demonstrou a ação que o menino da história realizou ao cair de bicicleta e machucar o braço. Essa ação manual, ainda que de natureza comunicativa - já que o narrador surdo está comunicando uma história ao seu interlocutor -, na verdade parece sobrepor a função semiótica do gesto (quando vista sob o ponto de vista da camada do narrador) com uma função ergótica do personagem (quando vista sob o ponto de vista da camada do personagem). Essa ocorrência nos faz pensar, portanto, em que medida o contínuo de Müller (2019) possibilitaria compreender as diferentes ações manuais de línguas orais e línguas de sinais dentro da complexidade semiótica de discursos narrativos (MCCLEARY; VIOTTI, 2011).

\footnotetext{
${ }^{3}$ A Teoria dos Espaços Mentais foi desenvolvida por Fauconnier $(1994,1997)$ e Fauconnier e Turner (2002).
} 


\section{REVISTA DA ABRALIN}

\section{Considerações finais}

A fim de discutir a relação entre gestos e sinais no âmbito da Linguística das Línguas de Sinais, tomamos a proposta teórica de Müller (2019) para, a partir da análise de dados, refletir criticamente sobre em que medida ela se aplicaria aos dados empíricos de Libras.

Nesse percurso, a adesão ao conceito teórico de multimodalidade se mostrou um ponto positivo da proposta, porém bastante sensível à descrição do funcionamento dos gestos/sinais em Libras, uma língua cujo canal de produção de ambos os fenômenos, "gesto" e "sinal", é o mesmo: o corpo. Essa coincidência da modalidade linguística e gestual acomoda-se no viés teórico que entende que a comunicação humana ocorre a partir do corpo, que é o que faz a língua emergir, mas rompe com classificações que distinguem de forma categórica o que nas línguas humanas se manifesta dinâmica e simultaneamente.

Compreendendo as quatro demarcações do contínuo proposto por Müller (2019) como marcos prototípicos, buscamos em nossos dados ocorrências de ações manuais que pudessem ser caracterizadas com base nos três parâmetros que a autora traz como relevantes: a convencionalidade, a composicionalidade e a relação forma-significado. Por meio dessa análise, hipotetizamos 55 sinais, 7 emblemas, 3 gestos recorrentes e 2 gestos singulares na história da pera estudada e buscamos apresentar 1 ou 2 exemplos de cada ocorrência, em virtude das limitações do escopo de um artigo.

Além de focar nessas quatro demarcações do contínuo, nossa análise buscou explorar possíveis processos de lexicalização de emblemas e gestos recorrentes em sinais, como Müller (2019) propõe. Sugerimos que o emblema de "traquinagem" que observamos tanto entre falantes do português quanto entre os de Libras pode ter se lexicalizado no sinal ANSIEDADE da Libras; sugerimos ainda que o gesto recorrente palm-up pode ter se lexicalizado nos sinais QUAL da Libras e O-QUE da língua de sinais americana. Em todos esses aspectos, a proposta teórica de Müller (2019) pareceu se mostrar adequada para a nossa análise de Libras.

No entanto, nossos resultados apontam também que algumas ações manuais levantam questões sobre o contínuo e sua aplicação em línguas orais e línguas de sinais. Um primeiro desafio foi o contraste entre uma ação que, no contexto de línguas orais, parece ser caracterizada como um emblema (“deixa pra lá!”) pelo fato de não ser decomponível, mas que na língua de sinais, apresentada exatamente da mesma forma, parece ser mais bem caracterizada como um sinal, já que contrasta com outros pares mínimos, como o sinal MAIS. Essa situação instiga a reflexão sobre em que medida uma mesma ação manual poderia apresentar características diferentes no contexto de línguas orais e línguas de sinais.

Uma segunda questão levantada diz respeito a ações manuais com funções discursivas, como as boias das línguas de sinais, que são manipuladas localmente pelos narradores. Em uma das ocorrências, o narrador mescla parte do sinal CHEI@ com as boias de listagem, ou quando manipula a boia TRÊS e produz uma boia DOIS com uma forma pouco convencional, aparentemente misturando em uma única ocorrência parâmetros que supostamente Müller (2019) distribui em diferentes pontos do contínuo. 


\section{REVISTA DA ABRALIN}

Por fim, argumentamos que, no que tange a narrativas, a produção de ações manuais no contexto de ação construída gera desafios para o contínuo, visto que o significado de tais ações manuais pode apresentar funções simultaneamente semióticas (do ponto de vista da camada do narrador) e ergóticas (do ponto de vista do personagem). Isso levanta questões sobre como o contínuo proposto por Müller (2019) trataria dos contextos de integração conceitual.

Nos anos mais recentes, a aproximação entre os estudos do gesto e a linguística das línguas de sinais tem se mostrado uma abordagem cada vez mais profícua para compreendermos melhor tanto as línguas de sinais quanto as línguas orais. Nesse contexto, a proposta de Müller (2019) apresenta a nosso ver uma importante contribuição, pois busca unificar a compreensão acerca das ações manuais de línguas orais e de sinais. Ainda assim, entendemos que a proposta da autora carece de fundamentação empírica, particularmente no âmbito das línguas de sinais. Especialmente sua sugestão de que todo sinal decente (resulta da lexicalização) de emblemas, a falta de previsão de que uma mesma ação manual possa ter valores diferentes a depender do contexto de uso e o fato de que a convencionalidade e a composicionalidade não parecem ser bons critérios para distinguir língua de gesto, uma vez que gestos também podem ser composicionais e convencionais.

Esperamos que este trabalho possa contribuir no sentido de demonstrar tanto seus potenciais quanto suas possíveis limitações, para que futuramente possamos chegar a uma compreensão das línguas humanas que reconheça seu caráter multimodal inerente.

\section{REFERÊNCIAS}

CADOZ, C. Le geste canal de communication homme/machine: la communication "instrumentale". Technique et Science Informatiques, v. 13, n. 1, p. 31-61, 1994. Disponível em: https://core.ac.uk/download/pdf/51963302.pdf. Acesso em: 28 jul. 2021.

CAPISTRANO JÚNIOR, R.; LINS, M. da P. P.; CASOTTI, J. B. C. Leitura, multimodalidade e ensino de língua portuguesa. PERcursos Linguísticos, v. 7, n. 17, p. 285-302, 2017. Disponível em:

https://periodicos.ufes.br/percursos/article/view/18532. Acesso em: 28 jul. 2021.

CHAFE, W. L. (ed.). The pear stories: cognitive, cultural, and linguistic aspects of narrative production. Norwood: Ablex, 1980. (Advances in Discourse Processes, v. 3).

COOPERRIDER, K.; ABNER, N.; GOLDIN-MEADOW, S. The palm-up puzzle: meanings and origins of a widespread form in gesture and sign. In: SANDLER, W.; GULLBERG, M.; PADDEN, C. (ed.). Visual language. Lausanne: Frontiers Media, 2019. p. 116-131.

ENFIELD, N. J. The anatomy of meaning: speech, gesture, and composite utterances. Cambridge: Cambridge University Press, 2009.

FAUCONNIER, G. Mappings in thought and language. 1.ed. Cambridge: Cambridge University Press. 1997. 205p.

FAUCONNIER, G. Mental spaces: aspects of meaning construction in natural language. 1.ed. Cambridge: Cambridge University Press. 1994. 


\section{REVISTA DA ABRALIN}

FAUCONNIER, G.; TURNER. M. The way we think: Conceptual blending and the mind's hidden complexities. 1.ed. New York: Basic Books. 2002. 440p

GERHARDT, T. E.; SILVEIRA, D. T. (org.). Métodos de pesquisa. Porto Alegre: Editora da UFRGS, 2009. Disponível em: https://lume.ufrgs.br/handle/10183/52806. Acesso em: 3 jul. 2021.

GESSER, A. Libras? que língua é essa: crenças e preconceitos em torno da língua de sinais e da realidade surda. São Paulo: Parábola, 2009.

GOLDIN-MEADOW, S. The impact of time on predicate forms in the manual modality: signers, homesigners, and silent gesturers. Topics in Cognitive Science, v. 7, p. 169-184, 2015. DOI: https://doi.org/10.1111/tops.12119. Disponível em: https://onlinelibrary.wiley.com/doi/10.1111/tops.12119. Acesso em: 28 jul. 2021.

GOLDIN-MEADOW, S.; BRENTARI, D. Gesture, sign, and language: the coming of age of sign language and gesture studies. Behavioral and Brain Sciences, v. 40, p. 1-17, 2017. DOI: https://doi.org/10.1017/S0140525X15001247. Disponível em: https://www.cambridge.org/core/journals/behavioral-and-brain-sciences/article/gesture-sign-andlanguage-the-coming-of-age-of-sign-language-and-gesture-studies /40B9B8E3C35C7005D4D588EC39E34C80. Acesso em: 28 jul. 2021.

HEITKOETTER, R. P.; XAVIER, A. N. Descrição e análise de boias de listagem em libras. Humanidades E Inovação, v. 7, n. 26, p. 85-111, 2020. Disponível em: https://revista.unitins.br/index.php/humanidadeseinovacao/article/view/3234. Acesso em: 28 jul. 2021.

JANZEN, T. Composite utterances in a signed language: topic constructions and perspective-taking in ASL. Cognitive Linguistics, v. 28, n. 3, p. 511-538, 2017. DOI: https://doi.org/10.1515/cog-2016-0121. Disponível em: https://www.degruyter.com/document/doi/10.1515/cog-2016-0121/html. Acesso em: 28 jul. 2021.

KENDON, A. Gesture: visible action as utterance. Cambridge: Cambridge University Press, 2004.

KENDON, A. Semiotic diversity in utterance production and the concept of 'language'. Philosophical Transactions of the Royal Society B, v. 369, n. 1651, 2014. DOI: https://doi.org/10.1098/rstb.2013.0293. Disponível em: https://royalsocietypublishing.org/doi/10.1098/rstb.2013.0293. Acesso em: 28 jul. 2021.

LAKOFF, G. Women, fire and dangerous things: what categories reveal about the mind. Chicago: University of Chicago Press, 1987.

LIDDEL, S. Grammar, gesture and meaning in American Sign Language. Cambridge: Cambridge University Press, 2003.

LIDDELL, S. K.; METZGER, M. Gesture in sign language discourse. Journal of Pragmatics, v. 30, n. 6, p. 657-697, 1998. DOI: https://doi.org/10.1016/S0378-2166(98)00061-7. Disponível em: https://www.sciencedirect.com/science/article/abs/pii/S0378216698000617?via\%3Dihub. Acesso em: 28 jul. 2021.

McCLEARY, L.; VIOTTI, E. Língua e gesto em línguas sinalizadas. Veredas, v. 15, n. 1, p. 289-304, 2011. Disponível em: https://www.ufjf.br/revistaveredas/files/2011/05/ARTIGO-212.pdf. Acesso em: 28 jul. 2021.

McCLEARY, L.; VIOTTI, E. Fundamentos para uma semiótica de corpos em ação. In: FIORIN, J. L. (ed.). Novos caminhos da linguística. São Paulo: Contexto, 2017. p. 171-193.

McNEILL, D. (ed.). Language and gesture. Cambridge: Cambridge University Press, 2000. 


\section{REVISTA DA ABRALIN}

MÜLLER, C. Gesture and sign: cataclysmic break or dynamic relations? In: SANDLER, W.; GULLBERG, M.; PADDEN, C. (ed.). Visual language. Lausanne: Frontiers Media, 2019. p. 29-48.

PEARFILM. [S. l.: s. n.], 2008. 1 vídeo (5 min 54 s). Publicado pelo canal Haiweongwas. Disponível em: https://www.youtube.com/watch?v=bRNSTxTpG7U. Acesso em: 28 jul. 2021.

SANDLER, W.; GULLBERG, M.; PADDEN, C. (ed.). Visual language. Lausanne: Frontiers Media, 2019.

SIGN LANGUAGE ONLINE. ASL sign for WHAT. [s.d.]. Disponível em:

https://www.handspeak.com/word/search/index.php?id=2383. Acesso em: 28 jul. 2021

SILVA, J. P. da. Demonstrações em uma narrativa sinalizada em libras. 2014. Tese (Doutorado em Semiótica e Linguística Geral) - Faculdade de Filosofia, Letras e Ciências Humanas, Universidade de São Paulo, São Paulo, 2014. DOI: https://doi.org/10.11606/D.8.2014.tde-07052015-170319. Disponível em:

https://www.teses.usp.br/teses/disponiveis/8/8139/tde-07052015-170319/pt-br.php. Acesso em: 28 jul. 2021.

UNIVERSIDADE FEDERAL DE SANTA CATARINA - UFSC. Corpus Libras. Florianópolis, 2014. Disponível em: http://www.corpuslibras.ufsc.br. Acesso em: 28 jul. 2021 